\title{
Intermolecular Heck Coupling with Hindered Alkenes Driven by Carboxylate Directivity
}

\author{
Tucker R. Huffman, Yebin Wu, Alexis Emmerich, Ryan A. Shenvi* \\ Department of Chemistry, The Scripps Research Institute, La Jolla, California 92037, United States
}

\section{Supporting Information Placeholder}

\begin{abstract}
Pd(0)-catalyzed, non-chain-walking Mizoroki-Heck reactions exhibit poor reactivity with polysubstituted, unbiased alkenes. Intermolecular reactions with simple, all-carbon tetrasubstituted alkenes are unprecedented. Here we report that pendant carboxylic acids, combined with bulky monophospine ligands on palladium, can direct the arylation of tri- and tetrasubstituted olefins. Quaternary carbons are established at high $\mathrm{Fsp}^{3}$ attached-ring junctures and the carboxylate directing group can be removed after coupling. Carboxylate directivity prevents over-arylation of the new, less hindered alkene, which can be diversified in subsequent reactions.
\end{abstract}

The Mizoroki-Heck reaction ${ }^{1}$ has become a staple of cross coupling and has transformed how molecules are synthesized. A large volume of research in the decades since its discovery has identified some limitations in its scope. ${ }^{2}$ For example, electronically unbiased, ${ }^{3}$ cyclic and sterically hindered olefins remain challenging substrates with low inherent reactivity and selectivity in traditional Heck arylations. ${ }^{4}$ Pioneering work from Sigman on the oxidative Heck reaction ${ }^{5}$ has enabled the regioselective arylation of trisubstituted linear alkenes followed by chain walking the unsaturation toward a polarizing functional group. In this powerful cross-coupling, the alkene is lost or transferred, and the canonical Heck product is not obtained. Intermolecular Heck reactions are unprecedented with all-carbon tetrasubstituted olefins, with the exception of strained hydrocarbons $^{6}$ like bicyclopropylidene. ${ }^{7}$ Here we show that potassium carboxylates serve as directing groups to enable single Heck reactions of tri- and tetrasubstituted alkenes, including hindered cyclic motifs. Products include $\mathrm{sp}^{2}-\mathrm{sp}^{3}$ attached-ring motifs and diversifiable unsaturated building blocks, otherwise inaccessible by cross-coupling methods.

Many different approaches have been applied to extend the classical Heck reaction to more traditionally challenging substrates (Figure 1). Early work by $\mathrm{Grigg}^{8}$ and Overman $^{9}$ demonstrated the utility of intramolecular Heck

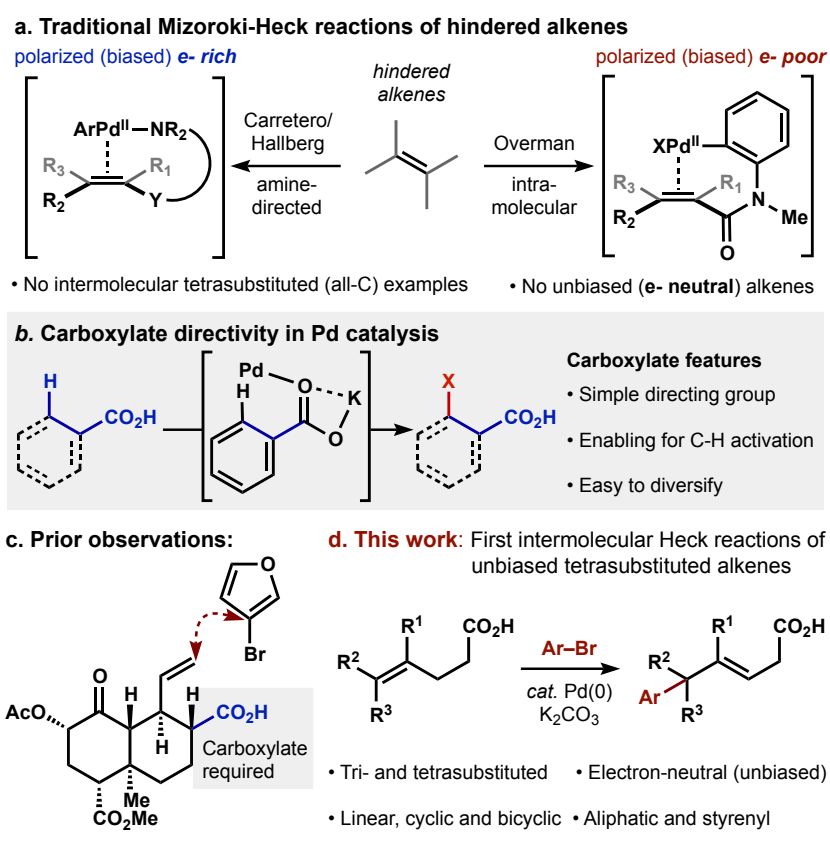

Figure 1: Approaches to the Heck reaction on challenging substrates.

reactions to overcome the reactivity barrier for highly substituted substrates, with their groups and others forging various spiro- and polycyclic systems from tri- and some tetrasubstiuted olefins. The reactivity enhancement from intramolecular delivery of the $\mathrm{Pd}^{\mathrm{II}}$-Ar species was leveraged in several directed Heck reactions. Notably, the groups of Carretero ${ }^{10}$ and Hallberg ${ }^{11}$ used tethered functional groups bearing basic nitrogens to relay stereochemical information, with the latter able to form quaternary centers from a fully-substituted, albeit polarized substrate. A seminal report from White and coworkers in 2008 established that oxidative Heck conditions could engage unbiased terminal olefins using weakly directing functional groups to yield terminally arylated products, ${ }^{12}$ and Sigman in 2014 extended his redox-relay Heck reaction to trisubstituted olefins with oxidative conditions. ${ }^{5}$ With the exception 
of enelactams, redox-relay Heck reactions do not tolerate cyclic substrates, which tend to yield mixtures of regioisomers. ${ }^{13}$

Heck reactions with sterically hindered and unbiased olefins remain non-trivial in many cases, evidenced by recent syntheses of $\kappa$-opioid receptor agonists 20 -nor-SalA ${ }^{14}$ and $\mathrm{O} 6 \mathrm{C}-20$-nor-SalA. ${ }^{15}$ A late-stage Heck arylation on a hindered, unbiased olefin could not be achieved using traditional or oxidative Heck conditions. However, incorporation of a carboxylic acid close to the alkene significantly accelerated arylation relative to deactivation of the palladium catalyst or decomposition of the aryl halide, 3bromofuran (Figure 1c). ${ }^{14}$ This effect is consistent with observations in Pd-catalyzed $\mathrm{C}-\mathrm{H}$ activation literature, where the carboxylic acid has emerged as a privileged directing group. ${ }^{16}$ We wondered if carboxylate-directivity could be applied more generally in the Heck reaction. ${ }^{17}$ Here we report that carboxylic acids accelerate and direct the intermolecular Heck reaction of tri- and tetrasubstituted olefins (Figure 1d). The reactivity enhancement of the carboxylate anion allows the formation of quaternary centers from linear, cyclic, bicyclic, aliphatic, and hindered styrenyl substrates. Carboxylate-directivity seems to inhabit a 'goldilocks region' among Mizoroki-Heck regimes: cationic-Pd conditions favor chain-walking into a terminating group ${ }^{5}$ and chelating directing groups prevent $\beta$-hydride elimination altogether. ${ }^{17}$ Carboxylate-directivity promotes regioselective engagement of hindered alkenes yet allows regio- and stereoselective $\beta$-hydride elimination without iterative arylation of the new, less hindered alkene.

We identified tetrasubstituted alkene 1a as a model substrate to explore and optimize carboxylate directivity (for a full table of optimization, see the Supporting Information). Type of base significantly influenced yield: sodium cation was inferior to potassium, and ammonium cation was ineffective, consistent with a $\kappa^{2}$ binding of alkali cation necessary to favor a $\kappa^{1} \mathrm{Pd}$-carboxylate and position the metal into the carbon chain ${ }^{16}$. Choice of phosphine proved crucial for efficiency and breadth of scope. Bisphosphines were ineffective, likely due to occupancy of the Pd valence necessary for carboxylate coordination (entries 4-5). Rapidly dissociating, larger bite-angle bisphosphines delivered small amounts of product (entry 6). A bulky monophosphine proved crucial to promote reaction, either favoring an $\mathrm{L}_{1} \mathrm{Pd}-\mathrm{Ar}$ species with open binding sites for both carboxylate and alkene, or dissociating from Pd to promote a cationic pathway. ${ }^{18}$ Interestingly, XPhos performed poorly, although it offered the highest yields in 20-nor-SalA. ${ }^{14}$ The arylation exhibits high regioselectivity, delivering the arene distal to the directing group, which is consistent with a 6-membered chelate of the carboxylate to the $\mathrm{Pd}^{\mathrm{II}}$-alkyl intermediate (see Scheme 2, below). In contrast to redoxrelay Heck reactions of trisubstituted olefins, the unsaturation does not migrate into conjugation with the carboxylic acid but remains adjacent to the newly formed quaternary center. Additionally, the alkene isomer preferentially formed is internal and trisubstituted rather than terminal and disubstituted. ${ }^{19}$

The carboxylic acid was essential for reaction: substrates containing weakly Lewis basic esters, alcohols, and amides were completely unreacted under the optimized conditions after 16 hours. Tertiary amine 7 reacted to low conversion and gave a complex mixture of arylated materials.

Table 1. Reaction Optimization.

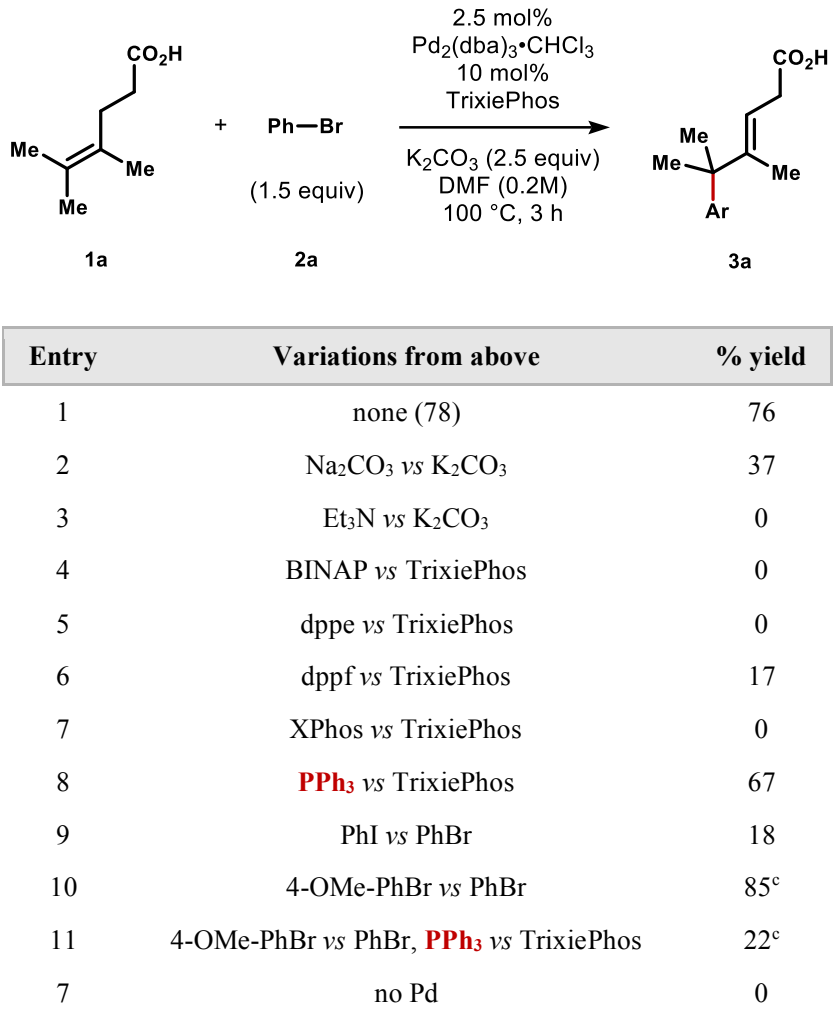

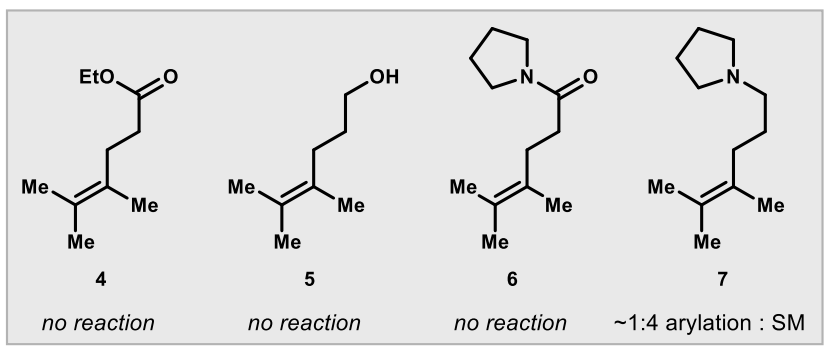

${ }^{a} 0.1 \mathrm{mmol}$ scale, yield determined by quantitative LCMS. ${ }^{b}$ n.r. $=$ no reaction observed by crude ${ }^{1} \mathrm{H}$ NMR after 16 hours; ${ }^{\mathrm{c}} \mathrm{Ar}=4$-OMe-Ph, ${ }^{1} \mathrm{H}$ NMR yield after $1 \mathrm{~h}$

The carboxylate-directed Heck was successfully applied to a wide range of tri- and tetrasubstituted olefins in modest to good yields after esterification (Table 2). Only olefins proximal to the carboxylic acid underwent reaction; the distal olefin of $\mathbf{3 d}$ was unreactive. In addition to simple linear aliphatic substrates, cyclic and styrenyl tri- and tetrasubstituted olefins were competent Heck partners. The intrinsic electronic bias of the styrene was completely overridden in the cases of $\mathbf{3 e}, \mathbf{3 f}$, and $\mathbf{3 m}$, giving valuable diarylated quaternary centers. Rearrangement of the styrene 
Table 2. Olefin Scope

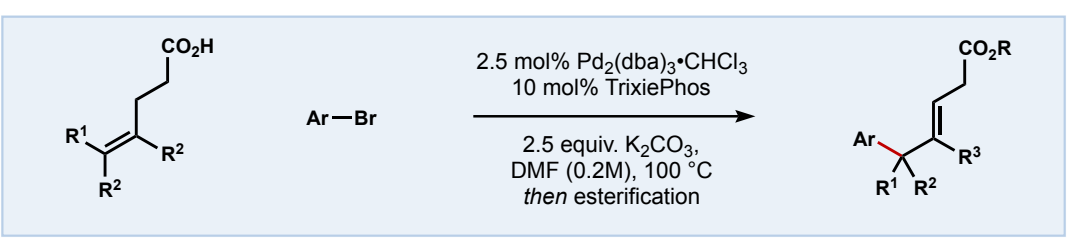

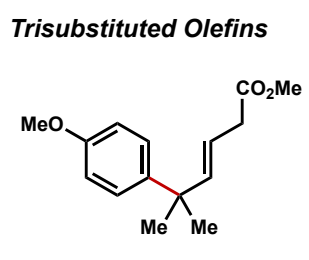

3b $(77 \%)$

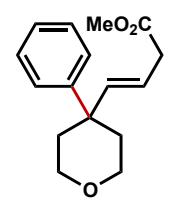

$3 g(61 \%)^{b}$

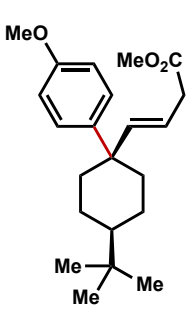

3k (58\%, 20:1 dr)

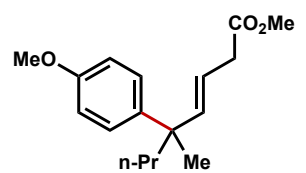

$3 \mathrm{c}(51 \%)$

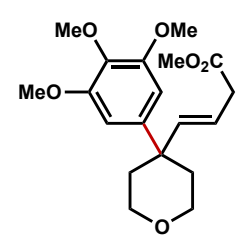

3h $(52 \%)^{b}$

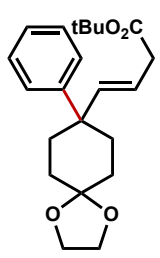

3I $(45 \%)^{b, d}$

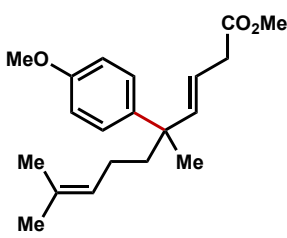

3d (53\%)
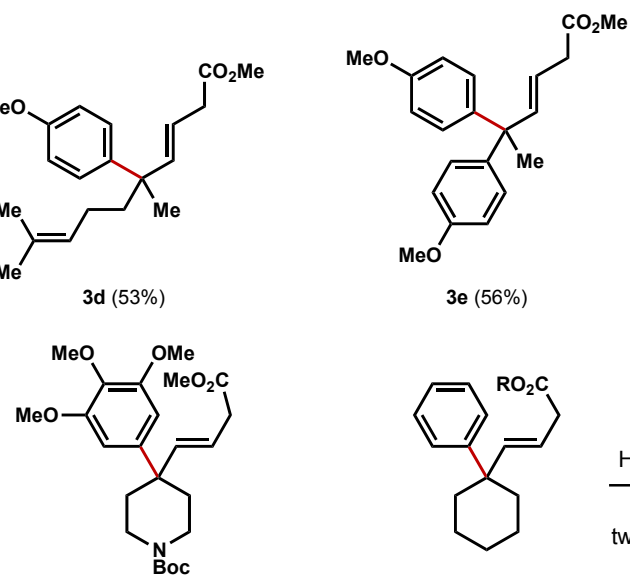

3i $(44 \%)^{\mathrm{b}, \mathrm{c}}$

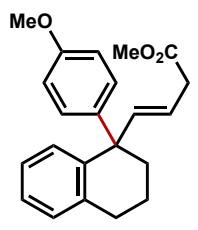

$3 m(43 \%)$ 3n $(32 \%, 5: 1 \mathrm{dr})$

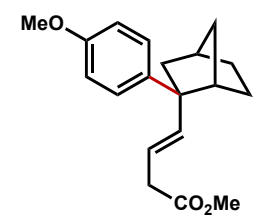

$3 e(56 \%)$

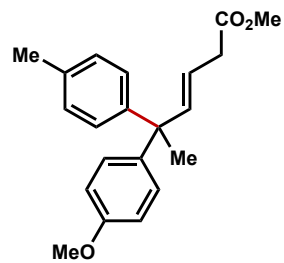

3f $(36 \%)$

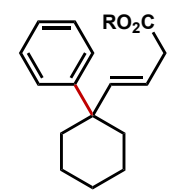

$\mathbf{R}=\mathbf{H}: \mathbf{3} \mathbf{j}$
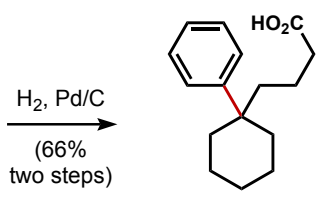

Overall: $57 \%$ (3 Steps) Ref 21: $\leq 22 \%$ (6 Steps)

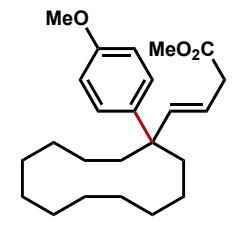

3o $(59 \%)$

Tetrasubstituted Olefins

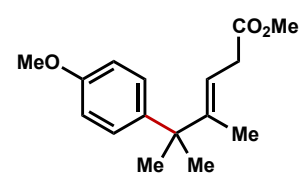

$3 p(71 \%)$<smiles>CC(=O)C(C)C=C(C)C(C)(C)c1ccccc1</smiles>

$3 q(46 \%)$

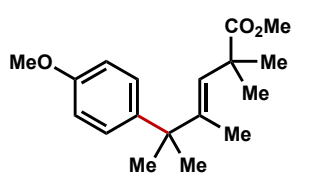

3 r (35\%)

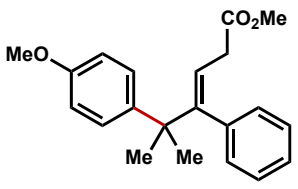

3s $(37 \%)$

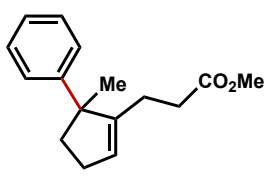

3t $(72 \%, 6: 1 \text { endo:exo })^{e}$

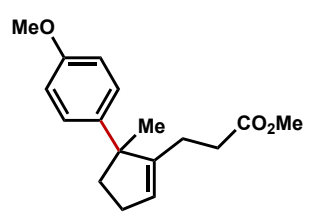

3u $(59 \%, 5: 2 \text { endo:exo })^{b, e}$

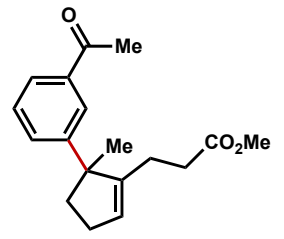

3v $(56 \%, 4: 1 \text { endo:exo })^{\mathrm{e}}$

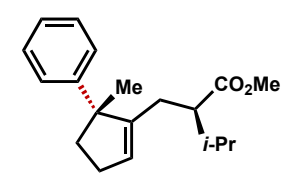

3w $\left(49 \%, 4: 1\right.$ endo:exo, 8:1 dr) ${ }^{e}$

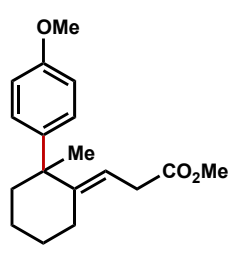

$3 \times(20 \%)$

${ }^{\mathrm{a}} 0.1 \mathrm{mmol}$ scale, isolated yield over 2 steps, reaction time $16 \mathrm{~h}$. Esterification conditions unless otherwise noted: $(\mathrm{COCl})_{2}(2$ eq), DCM (0.1M); $\mathrm{MeOH}$ (excess). ${ }^{\mathrm{b}} 1$ eqivalent of $\mathrm{ArBr}$ used. ${ }^{\mathrm{c}}$ Esterification: DIC, DMAP, MeOH, DCM. ${ }^{\mathrm{d}}$ Esterification: $N, N^{\prime}$-di ${ }^{i} \mathrm{Pr}-\mathrm{O}-{ }^{t} \mathrm{Bu}$ isourea, DCM. ${ }^{e}$ Ratio of endocyclic to exocyclic olefin products.

substitution did not change delivery of the arene electrophile (see 3s). The use of carbo- and heterocyclic olefins produced challenging all-carbon quaternary centers at $\mathrm{Csp}^{3}-\mathrm{Csp}^{2}$ attached-ring motifs, including the bicycle $\mathbf{3 n}$ and cyclododecane 3o. These motifs represent high frac- tion-sp ${ }^{3}\left(\mathrm{Fsp}^{3}\right)$ equivalents of biaryls and valuable scaffolds for medicinal chemistry. ${ }^{20}$ For example, phenyl substituted cyclohexane 8, an intermediate in the synthesis of S1P1 agonists, could be prepared in an improved 3 step route as compared to the reported 6 step sequence. ${ }^{21}$ Electron-rich 
bromoarenes performed well, in contrast to nickelcatalyzed hydroarylations, ${ }^{22}$ which also form quaternary carbons at attached-ring bridgeheads, but prefer electrondeficient iodoarenes.

Diastereoselectivity in the Heck reaction could be effected by: substitution $\alpha$ to the directing carboxylic acid, (3w), existing stereocenters on cyclic substrates (3k), or bridging-ring topology (3n). While most reactions in Table 2 were performed on small scale $(0.1 \mathrm{mmol})$, scale-up proved uneventful and allowed over $500 \mathrm{mg}$ of $\mathbf{3 u}$ to be prepared in one batch from the tetrasubstituted cyclopentene. $^{23}$

Table 3. Aryl halide scope with a tetrasubstituted alkene. ${ }^{a}$

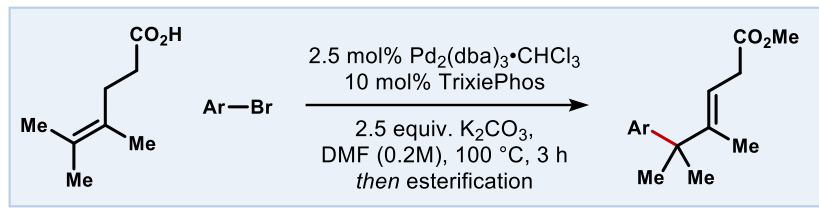

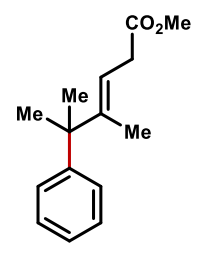

3y $(54 \%)$<smiles>COC(=O)CC=C(C)C(C)(C)c1ccc(OC(F)(F)F)cc1</smiles><smiles>COc1cc(C(C)(C)C(C)=CCC(N)=O)cc(OC)c1OC</smiles>

3ag (58\%)
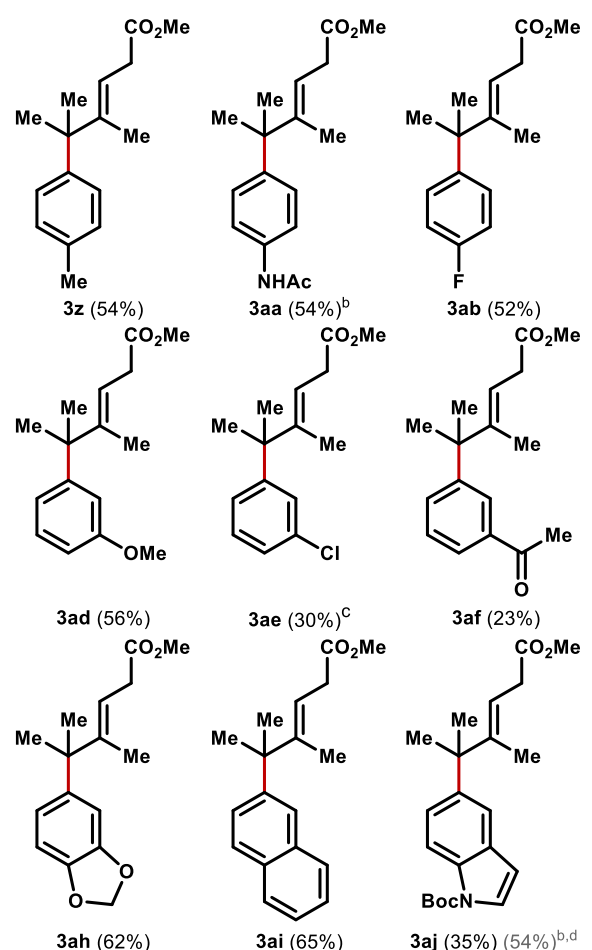

3aj $(35 \%)(54 \%)^{\mathrm{b}, \mathrm{d}}$
${ }^{a} 0.1 \mathrm{mmol}$ scale, isolated yield over 2 steps, reaction time $16 \mathrm{~h}$. Esterification conditions unless otherwise noted: $(\mathrm{COCl})_{2}(2 \mathrm{eq}), \mathrm{DCM}(0.1 \mathrm{M})$; $\mathrm{MeOH}$ (excess) ${ }^{\mathrm{b}}$ Esterification conditions: DIC, DMAP, $\mathrm{MeOH}, \mathrm{DCM}^{\mathrm{c}} 12: 1$ ratio of isomers favoring the internal ${ }^{\mathrm{d}}$ Combined yield including deprotected product.

Aryl scope is explored in Table 3 using tetrasubstituted substrate 1a. Para- and meta- substitution is well tolerated, and mono-, di-, and trisubstituted arenes could be installed with similar ease. Electron rich and electron neutral arenes outperform electron poor, with electron rich aryl bromides noted to complete fastest. Even highly electronrich trimethoxyphenyl product 3ag was delivered in good yield. Aryl bromides with strongly electron-withdrawing groups in the para position were found to stall at low conversion from apparent catalyst deactivation (see Scheme 2 and Supporting Information). Heterocycles were acceptable coupling partners in this chemistry, exemplified by benzodioxole 3ai and protected indole 3aj.

The products of carboxylate-directed Heck reaction exhibit high synthetic utility by virtue of the olefin and carboxylic acid functional groups, both of which are versatile synthetic handles. To demonstrate this versatility, we diversified $\mathbf{3} \mathbf{u}$ to form the densely functionalized products of Table 4. The olefin was capable of functionalization by Drago-Mukaiyama hydration, epoxidation, and dihydroxylation, and treatment of the dihydroxylation product with oxalyl chloride in methanol immediately furnished 5membered lactone 12. Formation of redox active ester in place of the methyl ester allowed straightforward decarboxylation or decarboxylative arylation. As a result, motifs that were previously inaccessible by Mizoroki-Heck chemistry can now be unmaseked and retrosynthetically transformed to unsaturated carboxylates.

Scheme 4. Product Diversification ${ }^{a}$
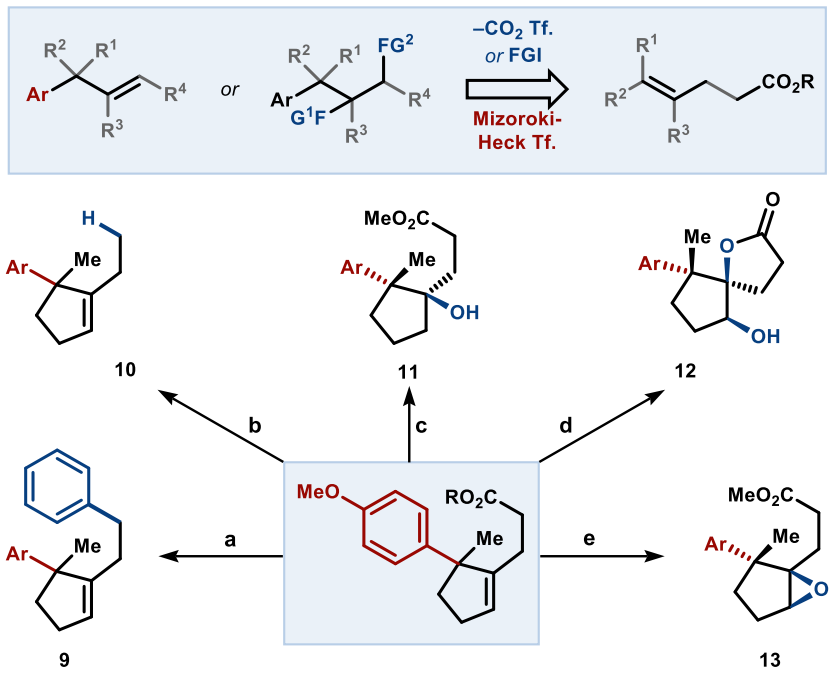

${ }^{a}$ Conditions: a) $\mathbf{R}=$ NHPI, $\mathrm{Ph}_{2} \mathrm{Zn}, \mathrm{Fe}(\mathrm{acac}) 2$, dppBz (34\%); b) $\mathbf{R}=\mathbf{N H P I}, \mathrm{Zn}^{0}, \mathrm{PhSiH}_{3}, \mathrm{NiCl}_{2} \bullet 6 \mathrm{H}_{2} \mathrm{O}(39 \%$; c) $\mathbf{R}=\mathbf{M e}$, $\left.\mathrm{Mn}(\mathrm{acac})_{2}, \mathrm{PhSiH}_{3}, \mathrm{PPh}_{3}, \mathrm{O}_{2}(64 \%, 2: 1 \mathrm{dr}) ; \mathrm{d}\right) \mathbf{R}=\mathbf{M e}, i$. $\mathrm{NMO}, \mathrm{OsO}_{4} ;$ ii. $\left.(\mathrm{COCl})_{2}, \mathrm{MeOH}(65 \%, 6: 1 \mathrm{dr}) ; \mathrm{e}\right) \mathbf{R}=\mathbf{M e}$, $m$-CPBA $(100 \%, 2: 1 \mathrm{dr})$

Several interesting mechanistic features are also worth noting. Although less-sterically hindered olefins were generated, over-arylation of products in Table 2 only occurred rarely and only in small quantities. The adjacent quaternary carbons were not responsible for enforcing single arylation: a homologated analog of the products in Tables 2 and 3 underwent facile carboxylate-directed Heck reaction $(\mathbf{1 4} \rightarrow \mathbf{1 5}$, Scheme $2 \mathrm{a})$ but the less hindered $\beta, \gamma$-unsaturated product (15) did not undergo arylation. Therefore, transition state geometry, not sterics, likely plays the primary role in effecting monoarylation. A low-energy, pseudochair conformation may be involved, which fits the regiochemistry of arylation and relative stereochemistry generated in 3w (Scheme 2b). This assembly would be geometrically unfavorable for $\beta, \gamma$-unsaturated products (15 and Tables 2 and 3 ).

Additionally, $\beta$-hydride elimination generates an olefin out of conjugation with the carboxylic acid, which suggests 
that chain-walking processes cannot occur. The preference for tetrasubstituted substrates to form the internal, trisubstituted olefin over the terminal 1,1-disubstituted olefin (see Table $3, c a$. $10: 1$ on average $)^{19,24}$ is striking given that statistics should favor $\beta$-hydride elimination to the terminal position. ${ }^{25}$ That the observed alkene isomer avoids the thermodynamic sink of conjugation and the statistically favored product suggests that the carboxylate directing group has a role enforcing $\beta$-hydride elimination, kinetically or thermodynamically, in addition to directing the regiochemistry of arene insertion. The superiority of TrixiePhos to engage hindered olefins was unexpected given its large size among monodentate phosphine ligands and may suggest that dissociation occurs prior to alkene coordination. Alternatively, the monoligated palladium $\mathrm{L}_{1} \mathrm{Pd}-\mathrm{Ar}$ favored by bulky phosphines ${ }^{26}$ may be necessary to allow coordination of both the carboxylate and the alkene. Another surprising feature was the poor performance of both aryl iodides and electron deficient aryl bromides, which typically couple well in Heck reactions but in our system led to catalyst deactivation. Analysis of the crude reaction mixture in reactions of electron poor arenes revealed formation of biaryls and LCMS peaks corresponding to substrate dehydrogenation. Catalyst deactivation possibly occurs downstream of reductive homocoupling to generate biaryls and inactive $\mathrm{Pd}^{\mathrm{II}}$ salts, ${ }^{27}$ a process that is bimolecular in $\mathrm{XPd}^{\mathrm{II}}$ $\mathrm{Ar}$ and would be disproportionality favored by rapid oxidative addition compared to the productive reaction pathway (Scheme 2c). This hypothesis also accounts for the superiority of sterically bulky ligands, which may prevent $\mathrm{Pd}^{\mathrm{II}}-\mathrm{Ar}$

a. Geometry biases against over-arylation
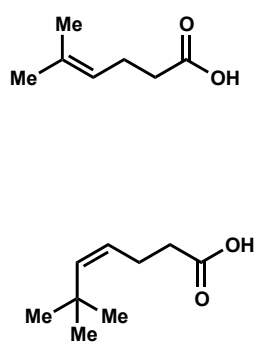

14

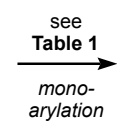

1 equiv. $\mathrm{PhB}$ $2.5 \mathrm{~mol} \%$ $\mathrm{Pd}_{2}(\mathrm{dba})_{3} \cdot \mathrm{CHCl}_{3}$
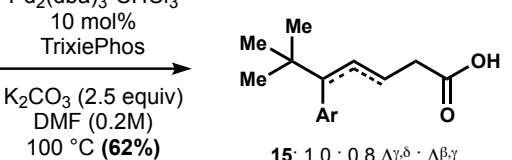

15: $1.0: 0.8 \Delta^{\gamma, \delta}: \Delta^{\beta, \gamma}$ b. Pseudo-chair transition state with $\kappa^{2}$-potassium carboxylate
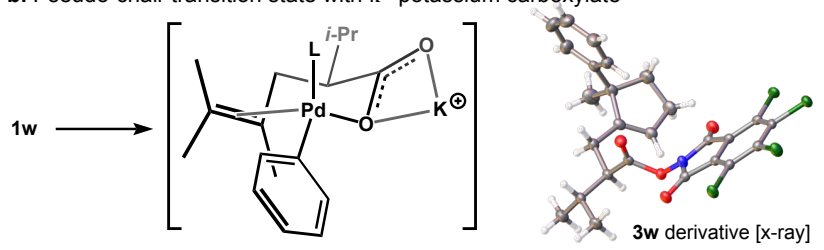

c. Productive and unproductive pathways proposed

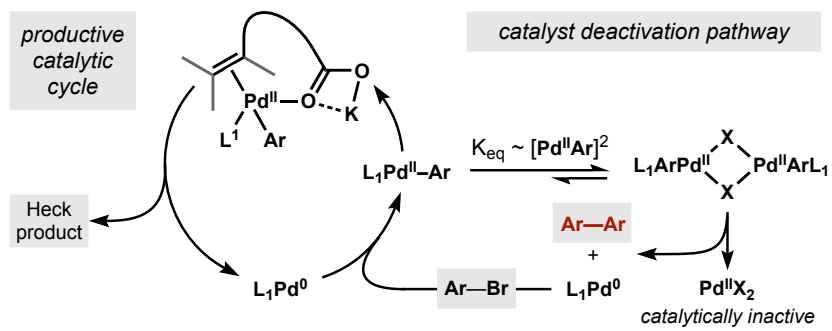

Scheme 2. Mechanistic model for regio- and stereochemistry. association leading to deactivation - a observation made previously in styrenyl Heck reactions. ${ }^{28}$

In conclusion, carboxylate-directivity advances the Heck reaction to a new milestone: the intermolecular coupling of tetrasubstituted alkenes. In addition to providing products of high synthetic value and utility, the success of this strategy underscores the profound rate enhancement imparted by carboxylate directing groups. ${ }^{16}$ The absence of chain walking and the regioselectivity of $\beta$-hydride elimination may point to a role of the carboxylate downstream of arene insertion. ${ }^{29}$ The insights gained from this work may be translatable to other modes of olefin crosscoupling.

\section{ASSOCIATED CONTENT}

\section{Supporting Information.}

The Supporting Information is available free of charge on the ACS Publications website.

Detailed experimental procedures, compound characterization, and spectral data (PDF)

\section{AUTHOR INFORMATION}

\section{Corresponding Author}

rshenvi@scripps.edu

\section{ACKNOWLEDGMENT}

Generous support was provided by the National Institutes of Health (R35 GM122606), Nanjing University of Science \& Technology (scholarship to Y. W.) and Westfälische Wilhelms-Universität Münster (scholarship to A. E.). We thank Zefeng Chen for early contributions to substrate scope and Jeremy J. Roach to early discovery efforts. Professors Keary Engle and Jin-Quan Yu are acknowledged for helpful input.

\section{REFERENCES}

1. T. Mizoroki, K. Mori, A. Ozaki, Bull. Chem. Soc. Jpn. 1971, 44, 581; b) R. F. Heck, J. P. Nolley, J. Org. Chem. 1972, 37, 2320.

2. For selected reviews and books, see: a) Heck, R. F. Acc. Chem. Res. 1979, 12, 146; b) Cabri, W.; Candiani, I. Acc. Chem. Res. 1995, 28, 2; c) Beletskaya, I. P.; Cheprakov, A. V. Chem. Rev. 2000, 100, 3009; d) Nicolaou, K. C.; Bulger, P. G.; Sarlah, D. Angew. Chem. Int. Ed. 2005, 44, 4442; b) Karimi, B.; Behzadnia, H.; Elhamifar, D.; Akhavan, P. F.; Esfahani, F. K.; Zamani, A. Synthesis, 2010, 1399.

3. Dieck, H. A.; Heck, R. F. J. Am Chem. Soc. 1974, 96, 1133.

4. a) Ref. 2a; b) Bates, Roderick. Organic synthesis using transition metals. John Wiley \& Sons, 2012, pg. 153190; c) Zheng, C.; Stahl, S. S. Chem. Commun. 2015, $51,12771$.

5. a) Werner, E.W.; Mei, T-S.; Burckle, A.J.; Sigman, M.S. Science.2012, 338, 1455; b) Mei, T.-S.; Werner, E.W.; Burckle, A.J.; Sigman, M.S J. Am. Chem. Soc. 
2013, 135, 6833; c) Xu, L.; Hilton, M. J.; Zhang, X.; Norrby, P.-O.; Wu, Y.-D.; Sigman, M.S.; Wiest, O. J. Am. Chem. Soc. 2014, 136, 1960; d) Mei, T.-S.; Patel, H. H.; Sigman, M. S. Nature 2014, 508, 344.

6. Dyker, G.; Körning, J; Jones, P. G.; Bubenitschek, P. Angew. Chem. Int. Ed. Engl. 1993, 32, 1733.

7. Bräse, S.; de Meijere, A. Angew. Chem. Int. Ed. 1995, 34, 2545.

8. Grigg, R.; Sridharan, Stevenson, P.; Worakun, T. J. Chem. Soc., Chem. Commun. 1986, 1697.

9. M. M. Abelman, T. Oh, L. E. Overman, J. Org. Chem., 1987, 52, 4130.

10. Buezo, N. D.; Alonso, I.; Carretero, J. C. J. Am. Chem. Soc. 1998, 120, 7129.

11. Nilsson, P.; Larhed, M.; Hallberg, A. J. Am. Chem. Soc. 2003, 125, 3430.

12. a) Delcamp, J. H.; Brucks, A. P.; White, M. C. J. Am. Chem. Soc., 2008, 130, 11270. b) Delcamp, J. H.; Gormisky, P. E.; White, M. C. J. Am. Chem. Soc. 2013, 135, 8460.

13. Yuan, Q.; Sigman, M. S. J. Am. Chem. Soc. 2018, 140, 6527.

14 Roach, J. J.; Sasano, Y.; Schmidt, C. L.; Zaidi, S.; Katritch, V.; Stevens, R. C.; Bohn, L. M.; Shenvi, R. A. ACS Cent. Sci., 2017, 3, 1329.

15 Hirasawa, S.; Cho, M.; Brust, T. F.; Roach, J. J.; Bohn, L. M.; Shenvi, R. A. Bioorganic Med. Chem. Lett. 2018, 28, 2770.

16. Engle, K. M.; Mei, T.-S.; Wasa, M.; Yu, J.-Q. Acc. Chem. Res., 2012, 45, 788.

17. For use of 8 -aminoquinoline directing groups for palladium catalyzed aryl-olefin cross-coupling, see: a) Yang, K.; Gurak, J. A., Jr.; Liu, Z.; Engle, K. M. $J$. Am. Chem. Soc. 2016, 138, 14705; b) Liu, Z.; Zeng, T.; Yang, K. S.; Engle, K. M. J. Am. Chem. Soc. 2016, 138, 15122; c) Liu, Z.; Wang, Y.; Wang, Z.; Zeng, T.; Liu, P.; Engle, K. M. J. Am. Chem. Soc. 2017, 139, 11261; d) Matsuura, R.; Jankins, T. C.; Hill, D. E.; Yang, K. S.; Gallego, G. M.; Yang. S.; He, M.; Wang, F.; Marsters, R.; McAlpine, I.; Engle, K. M. Chem. Sci. 2018, DOI: 10.1039/C8SC03081B.

18. Cabri, W.; Candiani, I.; Bedeschi, A. J. Org. Chem. 1993, $58,7421$.

19. A terminal olefin is not observed by ${ }^{1} \mathrm{H}$ NMR in the crude reaction mixtures. However, a diarylated compound arising from its intermediacy is occasionally present as a $\sim 10 \%$ impurity (see Supporting Information).

20.a) Lovering, F.; Bikker, J.; Humbolt, C. J. Med. Chem. 2009, 52, 6752; b) Brown, D. G.; Boström, J. J. Med. Chem. 2016, 59, 4443.

21. Das, J.; Soo Sung, K.; International Patent WO2012040532. 2012.

22. Green, S. A.; Vásquez-Céspedes, S.; Shenvi, R. A. J. Am. Chem. Soc. 2018, 140, 11317.

23. In some cases, excess aryl halide led to diarylation, which could be lessened through fewer equivalents of arene.
24. Small amounts of the alternative alkene regioisomer (1,1-disubstition) could be observed when electrondeficient arenes were used (3ac and 3ae), but the trisubstituted alkene still predominated 12:1.

25. In a companion paper by Engle and co-workers, a benzothiazole directing group promotes a remarkable, regioselective Heck arylation without chain walking. Tri- and tetrasubstituted alkenes, however, deliver a complex mixture of isomers. Professor Engle first noted the 'goldilocks' effect of our carboxylate-directivity on $\beta$-hydride elimination: the alkyl-palladium is not too stable and not too labile.

26. a) Hartwig, J. F. Angew. Chem., Int. Ed. 1998, 37, 2046; b) Martin, R.; Buchwald, S. L. Acc. Chem. Res. 2008, $41,1461$.

27. Attempts to rescue inactive $\mathrm{Pd}^{(\mathrm{II})}$ using stoichiometric reductants proved unsuccessful.

28. van Strijdonck, G. P. F.; Boele, M. D. K.; Kamer, P. C. J.; de Vries, J. G.; van Leewen, P. W. N. M. Eur. J. Inorg. Chem. 1999, 1073.

29. For carboxylate assistance in haloarene oxidative addition, see: Houpis, I. N.; Huang, C.; Nettekoven, U.; Chen, J. G.; Liu, R.; Canters, M. Org. Lett. 2008, 10, 5601 . 